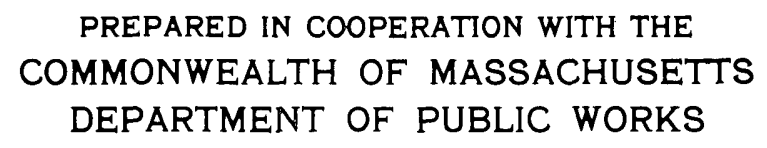

\title{
AEROMAGNETIC MAP OF THE NANTASKET QUADRANGLE SUFFOLK, NORFOLK, AND PLYMOUTH COUNTIES MASSACHUSETTS
}

\author{
GEOPHYSICAL INVESTIGATIONS \\ MAP GP-679
}

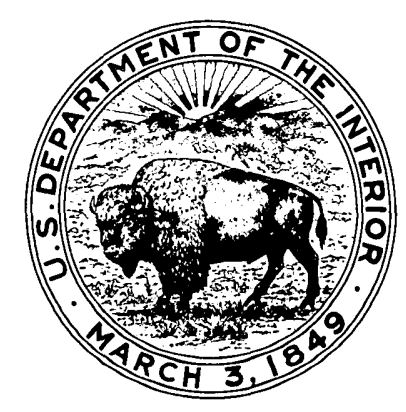

